\title{
The Clinical Profile of Nonmotor Fluctuations in Parkinson's Disease Patients
}

\author{
Dilek Ince Gunal, Kerim Nurichalichi, Nese Tuncer, Nural Bekiroglu, Sevinç Aktan
}

\begin{abstract}
Objective: Recently described nonmotor fluctuations may cause disability in Parkinson's disease patients. These fluctuations are generally grouped as sensory, autonomic and psychiatric. The clinical spectrum and frequency of these fluctuating symptoms are not well-described. Methods: We studied the relationship of nonmotor fluctuations with motor symptoms and determined the influence of age at disease onset, duration of disease, dosage and duration of levodopa treatment in the appearance of nonmotor fluctuations. Results: Statistical analysis showed a relationship of disease-related parameters with sensory and autonomic fluctuations but psychiatric fluctuations were only found to be associated with the duration of levodopa usage. The nonmotor fluctuations included in the study were observed during "on" periods as well as "off" periods. Conclusion: Nonmotor fluctuations had variable presentations. Moreover, their co-appearance with different types of motor fluctuations may be linked to the effect of other neurotransmitter systems acting synchronously with dopamine. Risk factors for sensory and autonomic fluctuations in patients with Parkinson's disease were early age of disease onset, longer duration and higher dose of levodopa use. Psychiatric fluctuations were only associated with higher doses of levodopa.
\end{abstract}

RÉSUMÉ: Le profil clinique des fluctuations non motrices chez les patients atteints de la maladie de Parkinson. Objectif: Les fluctuations non motrices décrites récemment peuvent être invalidantes chez les parkinsoniens. Ces fluctuations sont généralement sensitives, neurovégétatives ou psychiatriques. Le spectre clinique et la fréquence de ces symptômes fluctuants n'ont pas été décrits avec précision. Méthodes: Nous avons étudié la relation entre les fluctuations non motrices et les symptômes moteurs et nous avons déterminé l'influence de l'âge de début de la maladie, la durée de la maladie, le dosage et la durée du traitement par la lévodopa par rapport à l'apparition des fluctuations non motrices. Résultats: L'analyse statistique a montré une relation entre les paramètres reliés à la maladie et les fluctuations sensitives etneurovégétatives. Cependant les fluctuations psychiatriques n'ont été associées qu'à la durée de l'utilisation de la lévodopa. Les fluctuations non motrices incluses dans l'étude étaient observées tant pendant les périodes "on" que pendant les périodes "off". Conclusion: La présentation des fluctuations non motrices était variable. De plus, leur présence associée à différents types de fluctuations motrices peut être en relation avec l'effet d'autre systèmes de neurotransmetteurs en synchronie avec la dopamine. Les facteurs de risque des fluctuations sensitives et neurovégétatives chez les parkinsoniens étaient un âge de début précoce ainsi qu'une posologie élevée de lévodopa et une durée de traitement plus longue. Les fluctuations psychiatriques n'étaient associées qu'avec une posologie plus élevée de lévodopa.

Can. J. Neurol. Sci. 2002; 29:61-64

All patients with Parkinson's disease (PD) experience motor fluctuations, usually related to chronic levodopa therapy during the course of the disease. These fluctuations constitute the greatest problem for the long-term management of these patients. ${ }^{1}$ It is estimated that each year approximately $10 \%$ of all patients treated with levodopa will develop motor fluctuations, so that $50 \%$ will be affected after five years of sustained levodopa therapy. ${ }^{2}$ Recently, nonmotor fluctuations have been described, such as sensory, autonomic and psychiatric, in addition to motor fluctuations. ${ }^{3}$ The aims of this study were firstly to determine nonmotor symptoms and secondly to estimate the relationship of nonmotor symptoms to motor fluctuations. Furthermore, the relationship between nonmotor fluctuations and age at disease onset, duration of disease, dosage and duration of levodopa use were studied.

From the Department of Neurology (DIG, KN, NT, SA), and Department of Biostatistics (NB), Marmara University Hospital, Altunizade 81190, Istanbul, Turkey ReCEIVED OCTOBER 10, 2000. ACCEPTED INFINALFORM August 8, 2001.

Reprint requests to: Dilek Ince Gunal, Marmara University Hospital Neurology Department, Altunizade 81190 Istanbul, Turkey. 


\section{METHODS}

During a six month period (November 1998 through April 1999) we evaluated 85 consecutive PD patients. The study was approved by our University ethics committee and informed consent was obtained from all patients. In a nondirected fashion, each patient was assessed by a standard questionnaire including sensory, autonomic and psychiatric symptoms. After determination of nonmotor symptoms, the relation of these to motor fluctuations was questioned by the same investigator (KN). Nonmotor symptoms occurring episodically and periodically, rather than continuously, and related to one of the motor fluctuations described below, were named "nonmotor fluctuations". Motor fluctuations were described to the patients as follows: "on" period was with the least amount of slowness, stiffness and "shakiness", whereas "off" period was the period with the highest level of slowness, stiffness and "shakiness". The "dyskinesia" period was characterized by abnormal, nonrhythmical involuntary movements. The patient's age at disease onset, duration of the disease, dosage and duration of levodopa usage were determined. The unified Parkinson's disease rating scales (UPDRS) and Hoehn and Yahr (H\&Y) scales of the patients were evaluated during "on" periods by the same investigator $(\mathrm{KN})$. The patients were also assessed by the MiniMental Status Scale to exclude the possibility that cognitive decline interfered with the interview performance (all patients had scales greater than 25/30). The nonmotor fluctuations were classified as sensory, autonomic and psychiatric. Using the student $t$ test, patients with or without these were compared with regard to the age at disease onset (year), duration of disease and levodopa usage (year). For levodopa doses (mg/day), a chi square test was used. Hoehn and Yahr and UPDRS scales of the patients with nonmotor fluctuations and without fluctuations were evaluated statistically by t-test. Pvalues less than 0.05 were considered statistically significant $(p<0.05)$. Values were reported as mean $\pm \mathrm{SD}$.

\section{RESULTS}

The 85 patients included in the study consisted of 50 men and 35 women. The mean age of the patients was 66.2 \pm 9.3 (range 38 to 85 ). The age at disease onset, duration of disease, dosage and

Table I: Demographic data of the study

\begin{tabular}{lcr}
\hline & Mean & Range \\
Age & $66.2 \pm 9.3$ & $(38-85)$ \\
Age of disease onset & $58.9 \pm 10.7$ & $(31-83)$ \\
Disease duration (year) & $7.8 \pm 6.1$ & $(0.5-33)$ \\
Duration of levodopa usage (yr ) & $4.7 \pm 4.3$ & $(0.5-25)$ \\
Levodopa dose/day (mgr) & $531.1 \pm 173.8$ & $(62.5-750)$ \\
& & \\
H\&Y & Median & Range \\
UPDRS & 2.16 & $(1-5)$ \\
& 40.49 & $(5-122)$ \\
\hline
\end{tabular}

H\&Y: Hoehn and Yahr scale

UPDRS: Unified Parkinson's Disease Rating Scale
Table 2: The questionnaire for the nonmotor fluctuations

\begin{tabular}{|c|c|c|c|c|}
\hline & $\begin{array}{l}\text { Tumber } \\
\text { patients }\end{array}$ & Off period & On period & Dyskinesia \\
\hline \multicolumn{5}{|l|}{ Sensory fluctuations } \\
\hline Pain & 23 & 23 & & \\
\hline Paresthesiae & 17 & 17 & & \\
\hline Akathisia & 11 & 11 & & \\
\hline Restless legs & 5 & 5 & & \\
\hline \multicolumn{5}{|l|}{ Autonomic fluctuations } \\
\hline Pallor of skin & 0 & & & \\
\hline Drooling & 6 & 5 & 1 & \\
\hline Difficulty with swallowing & 5 & 3 & 2 & \\
\hline Excessive gas & 4 & 2 & 2 & \\
\hline Bloating & 3 & 2 & 1 & \\
\hline Episodic spasm of anus & 0 & & & \\
\hline Shortness of breath & 2 & 2 & & \\
\hline Excessive sweating & 11 & 10 & 1 & \\
\hline Flashing or chilling & 9 & 8 & 1 & \\
\hline Frequent urination & 3 & 1 & 2 & \\
\hline Postural lightheaded-ness * & 2 & 2 & & \\
\hline \multicolumn{5}{|l|}{ Psychiatric fluctuations } \\
\hline Hallucinations & 3 & 2 & 1 & \\
\hline Moaning and screaming & 2 & 2 & & \\
\hline Elevated mood & 1 & & 1 & \\
\hline Depressed mood & 9 & 9 & & \\
\hline Panic attack & 1 & 1 & & \\
\hline
\end{tabular}

* based on history (not on examination)

duration of levodopa usage and scales are given in Table 1. Only five of the 85 patients were using dopamine receptor agonists in addition to immediate release levodopa preparations. None of the patients was on antidepressive, antipsychotic or anticholinergic medication.

Motor fluctuations: Seventy-two of 85 patients (84.7\%) had motor fluctuations. All of these patients experienced one or more nonmotor symptom. The fluctuations of these nonmotor symptoms and their relation with motor fluctuations were studied by classifying symptoms into sensory, autonomic and psychiatric (Table 2).

Sensory fluctuations: Fifty-nine of 72 patients (69.4\%) had sensory symptoms. These symptoms were associated with motor fluctuations in 28 patients (38.8\%) and all occurred during "off" periods. The sensory fluctuations were significantly higher in patients with early age of disease onset, long disease duration, high levodopa dosage and long duration of levodopa usage. The results are shown in Table 3.

Autonomic fluctuations: Sixty-one of 72 patients (84.7\%) had autonomic symptoms. Only 29.2\% (21 patients ) associated their symptoms with motor fluctuations. Autonomic fluctuations were during "off" periods in $74.2 \%$ and during "on" periods in 
Table 3: Correlation of disease related parameters with the occurrence of nonmotor fluctuations

\begin{tabular}{|c|c|c|c|c|}
\hline & Age at disease onset & $\begin{array}{l}\text { Disease duration } \\
\quad(\text { year } \pm \text { SD })\end{array}$ & $\begin{array}{c}\text { Duration of levodopa } \\
\text { use (year } \pm \text { SD) }\end{array}$ & $\begin{array}{c}\text { Levodopa } \\
\text { dose } \mathrm{mg} / \mathrm{d} \pm \mathrm{SD}\end{array}$ \\
\hline The patients with sensory fluctuations & $54.8 \pm 11.1 * *$ & $8.7 \pm 7.6 *$ & $6.1 \pm 5.6 *$ & $564.9 \pm 177.2 *$ \\
\hline The patients without sensory fluctuations & $62.2 \pm 9.6$ & $5.3 \pm 4.0$ & $3.4 \pm 3.4$ & $458.7 \pm 183.7$ \\
\hline The patients with autonomic fluctuations & $54.9 \pm 10.5 *$ & $9.2 \pm 6.7 *$ & $6.5 \pm 6.1 *$ & $571.4 \pm 191.9 *$ \\
\hline The patients without autonomic fluctuations & $61.3 \pm 10.3$ & $5.57 \pm 5.0$ & $3.4 \pm 3.3$ & $465.9 \pm 178.7$ \\
\hline The patients without psychiatric fluctuations & $59.7 \pm 10.5$ & $5.9 \pm 4.9$ & $4.3 \pm 4.6$ & $475.7 \pm 185.9$ \\
\hline
\end{tabular}

Values are mean $\pm \mathrm{SD}$

$* \mathrm{p}<0.05 ; * * \mathrm{p}<0.005$

$25.8 \%$ of the patients. Seven patients reported more than one autonomic symptom. Similar to sensory fluctuations, autonomic fluctuations were significantly higher in patients with early age of disease onset, long disease duration, high levodopa dosage and long duration of levodopa use. The results are shown in Table 3.

Psychiatric fluctuations: Thirty-four of 72 patients (47.2\%) had psychiatric symptoms and $11(15.3 \%)$ associated their symptoms with motor fluctuations. These psychiatric fluctuations were during "off" periods in $81.8 \%$, and during "on" periods in $18.2 \%$ of the patients. We did not find a significant difference between patients with and without psychiatric fluctuations with regard to age at disease onset, duration of disease and levodopa usage. On the contrary, higher doses of levodopa were associated with the occurrence of psychiatric fluctuations $(\mathrm{p}<0.05)$, (Table 3).

Hoehn and Yahr and UPDRS results of the patients with and without nonmotor fluctuations were compared and both scales were significantly higher in nonmotor fluctuating patients $(\mathrm{p}<0.05)$.

\section{Discussion}

The results of this study showed that nonmotor sensory fluctuations occurred most frequently in patients with an early age at disease onset, patients with long disease duration as well as patients with long duration of levodopa use. The dose of levodopa used was higher in these patients.

The clinical spectrum and frequency of nonmotor symptoms among patients with fluctuating PD are not well-known. Hillen et $\mathrm{al}^{3}$ studied nonmotor fluctuations in 130 consecutive PD patients. They emphasized the recognition of these symptoms as "off" phenomena. In our study group, the sensory fluctuations were the most frequent $(38.8 \%)$ among nonmotor fluctuations and were present during "off" periods, whereas the autonomic fluctuations occurred during "on" as well as "off" periods. These findings support the idea that nonmotor fluctuations are not exclusive to the "off" period. The psychiatric fluctuations largely appeared during "off" periods, except mood elevation which was reported during "on" periods in $18.2 \%$ of the patients. Nonmotor sensory fluctuations might be related to dopaminergic mechanisms. However, "on" period fluctuations and unresponsiveness to dopaminergic treatment strategies may indicate the influence of other neurotransmitter systems on the nonmotor fluctuations.

Autonomic symptoms were frequent among our patients $(84.7 \%)$ but only $33 \%$ were related to motor fluctuations. The autonomic fluctuations seen during "off" periods were increased salivation, abdominal bloating, sweating, facial flushing and postural lightheadedness (based on history). The patients with autonomic fluctuations had similar clinical characteristics to patients having sensory fluctuations: early age at disease onset, long disease duration and levodopa usage, and high levodopa doses associated with autonomic fluctuations. Autonomic fluctuations showed variability in timing with respect to motor fluctuations. This may suggest involvement of other neuroanatomic structures beyond nigral degeneration. For instance, hypothalamic involvement has been described in PD. ${ }^{4,5}$

Fluctuating psychiatric symptoms are frequently reported in PD. ${ }^{6}$ Two thirds of patients receiving chronic levodopa treatment experience mood fluctuations. ${ }^{1}$ Any combination of depression, anxiety, ${ }^{7}$ panic, ${ }^{8}$ irritability or apathy during "off" periods has been reported. Delis et $\mathrm{al}^{9}$ found a moderate impairment of neuropsychological tests during "off" periods. Likewise, we observed a mood decline during the period of worsening in the motor symptoms. In recent reports, mood fluctuations seen in PD patients have been studied extensively and a depressive mood has also been shown during the "dyskinesia" period. ${ }^{9}{ }^{10}$ In the present study, psychiatric fluctuations could not be associated with age at disease onset, duration of disease or levodopa usage, whereas levodopa dosage was significantly higher in fluctuating patients. The relationship found between the levodopa dose and psychiatric fluctuations might be a direct effect of levodopa but we could not explain the absence of a relationship between duration of levodopa use and psychiatric fluctuations. This might indicate that psychiatric fluctuations progress in a different manner from sensory and autonomic fluctuations.

The role of dopaminergic stimulation in nonmotor fluctuations is also not known. ${ }^{11}$ Some authors suggest that other neurotransmitters fluctuating synchronously with dopamine explain this role, since some of the nonmotor symptoms fluctuate in response to dopaminergic therapy but others are 
unchanged. ${ }^{12,13}$ This aspect of nonmotor fluctuations may be linked to noradrenergic, serotonergic or other secondary transmitter systems, the roles of which have not yet been clarified. ${ }^{13,14}$

\section{REFERENCES}

1. Quinn NP. Classification of fluctuations in patients with Parkinson's disease. Neurology 1988;51(suppl 2):25-29.

2. Poewe WH. Clinical aspects of motor fluctuations in patients with Parkinson's disease. Neurology 1994;44 (suppl 6):6-9.

3. Hillen ME, Sage JI. Nonmotor fluctuations in patients with Parkinson's disease. Neurology 1996;47:1180-1183.

4. Goetz CG, Lutge W, Tanner CM. Autonomic dysfunction in Parkinson's disease. Neurology 1996;36:73-75.

5. Langston JW, Forno LS. Hypothalamus in Parkinson's disease. Ann Neurol 1978;3:129-133.

6. Olanow CW, Koller WC. An algorithm for the management of Parkinson's disease. Treatment guidelines. Neurology 1988; 50(suppl 3):23-30.
7. Routh LC, Black JL, Ahlshog JE. Parkinson's disease complicated with anxiety. Mayo Clin Proc 1987;62:733-735.

8. Vasquez A, Jimenez FJ, Garcia-Ruiz P. Panic attacks in Parkinson's disease. Acta Neurol Scand 1993;87:14-18.

9. Delis D, Direnfeld L, Alexander MP, Kaplan E. Cognitive fluctuations associated with on-off phenomenon in Parkinson's disease. Neurology 1982;32:1049-1052.

10. Siemers ER, Shekhar A, Quaid K, Dickson H. Anxiety and motor performance in Parkinson's disease. Mov Disord 1993;8:501506.

11. Riley DE, Lang AE. The spectrum of levodopa-related fluctuations in Parkinson's disease. Neurology 1993;43:1459-1464.

12. Nissenbaum H, Quinn NP, Brown RG, et al. Mood swings associated with the "on-off" phenomenon in Parkinson's disease. Psychol Med 1987;17:899-904.

13. Sage JI, Mark MH. Basic mechanisms of motor fluctuations. Neurology 1994;44(suppl 6):10-14.

14. Quinn NP, Lang AE, Koller WC, Marsden CD. Painful Parkinson's disease. Lancet 1986;14:1366-1369. 